\title{
Anxiety and depression in women hospitalized due to high-risk pregnancy: An integrative quantitative and qualitative study
}

\author{
Martina Smorti ${ }^{1}$ (D) $\cdot$ Francesca Ginobbi $^{1} \cdot$ Tommaso Simoncini $^{2}$ (D) $\cdot$ Federica Pancetti $^{3}$ (D) $\cdot$ Alessia Carducci $^{1}$. \\ Giulia Mauri $^{1}$ - Angelo Gemignani ${ }^{1}$ (D)
}

Accepted: 21 May 2021 / Published online: 28 May 2021

(C) The Author(s) 2021

\begin{abstract}
Literature has shown that hospitalized women with high-risk pregnancy tend to develop anxious and depressive symptoms. Research has used quantitative or qualitative methods. By integrating both quantitative and qualitative methods, this study aims to analyze: a) the level of depression, anxiety, and pregnancy-related anxiety in a group of women hospitalized with high-risk pregnancy (hospitalized high-risk) compared with a group of non-hospitalized women with low-risk pregnancy; b) the content of hospitalization-related emotions in a high-risk group. A cross-sectional study was conducted on 30 hospitalized high-risk pregnant women and 32 women with low-risk pregnancy. Participants completed the Edinburgh Postnatal Depression Scale, Hospital Anxiety and Depression Scale (Anxiety), and Pregnancy Related Anxiety Questionnaire. The hospitalized high-risk group also completed open-ended questions about emotions experienced during hospitalization. Univariate Analysis of Covariance showed that the hospitalized high-risk group reported higher general anxiety and depression than the low-risk pregnancy group. Low-risk group reported higher level of concerns about own appearance than high-risk group. Narratives showed that the anxious and depressive symptoms of hospitalized women are related to the loneliness of being away from family. Despite attempts to understand hospitalization, they express concerns about pregnancy. Psychological support for hospitalized pregnant women should be provided to facilitate the communication of emotions that leads women to elaborate the experience of hospitalization to better adapt and cope with the critical condition.
\end{abstract}

Keywords High-risk pregnancy $\cdot$ Hospitalization $\cdot$ Standardized questionnaire $\cdot$ Narratives $\cdot$ Anxiety $\cdot$ Depression

\section{Introduction}

When a woman becomes pregnant, she enters a period of identity, couple, and relational instability (Hennekam, 2016; Smorti et al., 2019). Relationships with members of the family are redefined, the woman faces a maturation crisis, and new needs emerge (Bibring, 1959). When a healthy (or low-risk) pregnancy becomes a high-risk pregnancy, the woman

Martina Smorti

martina.smorti@unipi.it

1 Department of Surgical, Medical and Molecular Pathology and Critical Care Medicine, University of Pisa, Via Savi 10, 56126 Pisa, Italy

2 Department of Reproductive Medicine and Child Development, Division of Obstetrics and Gynaecology, University of Pisa, Pisa, Italy

3 Division of Obstetrics and Gynaecology, Department of Clinical and Experimental Medicine, University of Pisa, Pisa, Italy undergoes a healthy to illness transition (Kralik et al., 2006). This illness transition represented by high-risk pregnancy have a negative impact on psychological health (Dagklis et al., 2016). A high-risk pregnancy is defined as the condition in which the mother, fetus, or newborn is at a higher risk of death, disability, or disease (James et al., 2010). Examples of conditions that may lead to high-risk pregnancy are important maternal pathologies, such as gestational hypertension, preeclampsia, gestational diabetes (Bateman et al., 2013), as well as conditions that increase the risk for preterm birth, such as preterm rupture of membranes or fetal growth restriction (Queenan, 2012). Preterm birth, with a rate of $9 \%$ in higher income countries, is a major challenge in perinatal health care. It is associated with perinatal mortality, long-term neurological disability, admission to neonatal intensive care, and so on (World Health Organization, 2012). The most common treatment for prevention of preterm birth in the United States is antepartum bed rest and, in some cases, hospitalized bed rest (Maloni, 2010). Preterm birth has many causes, including psychological, social, and behavioral factors (Behrman \& 
Butler, 2007). Pregnancy-specific stress, severe life events, and high anxiety increase the risk for adverse maternal and fetal outcomes (Class et al., 2011). Hospitalization represents an additional stress for women, due to concerns for family management, which increases the risk of psychopathological symptoms (Dagklis et al., 2016; Denis et al., 2012; Fairbrother et al., 2016; Thiagayson et al., 2013). The purpose of this article is to analyze levels of depressive and anxious symptoms in hospitalized women with pregnancy at high-risk for preterm delivery and investigate their concerns.

Many studies have explored the presence of anxious and depressive symptoms in women hospitalized due to high-risk pregnancy (WHHRP).

Studies carried out according to a quantitative methodology, have tried to quantify, by means of standardized questionnaires, the level of anxious or depressive symptoms. Investigations conducted in this field have shown that hospitalized women present a risk of developing depression and general anxiety, and that this risk is higher than that found in women with a low-risk pregnancy (LRP) (Byatt et al., 2014; Denis et al., 2012; Fairbrother et al., 2016; Gourounti et al., 2015; Pisoni et al., 2016). Moreover, antenatal depression and anxiety are highly prevalent in a sample of WHHRP (Gourounti et al., 2015; Thiagayson et al., 2013). A Greek study on the incidence of these symptoms showed that almost $50 \%$ of WHHRP presented a high level of depression, and most of them had high general anxiety levels (Gourounti et al., 2015). Less investigated is the level of anxiety concerning gestation in hospitalized pregnant women. This theme appears to be relevant, given that anxiety specifically related to fear for infant health and childbirth have been shown to be associated with negative infant outcomes (Huizink et al., 2002; Rini et al., 1999). Research conducted by Denis et al. (2012) showed that women with high-risk pregnancy presented anxiety and concern both for physical restrictions and for the pregnancy itself, specifically related to fear of childbirth and fear for the health of the baby (Denis et al., 2012). However, in this study, the sample was composed of both hospitalized women (a small percentage) and women who required home bed rest (a greater percentage). Therefore, it was not possible to analyze the specific impact of hospitalization, but rather the impact of bed rest in high-risk pregnancy (Denis et al., 2012). To our knowledge, any other study has analyzed the level of anxiety related to pregnancy in hospitalized pregnant women.

The analysis of quantitative levels of anxiety and depression in WHHRP, although worthy of attention, given that it allows us to quantify the level of symptomatology, presents some limitations due to the heterogeneity of sample both for gestational age (i.e. 8-36 weeks) (Denis et al., 2012; Gourounti et al., 2015), definition of risk pregnancy (risk for preterm delivery vs. general high risk), and for inclusion criteria (only hospitalized women vs. hospitalized and home bed rest) (Denis et al., 2012). Consequently, the generalization of results of quantitative studies must be made with caution. Moreover, it must be acknowledged that quantitative studies do not allow, per se, an understanding of the subjective psychological experience of these women.

To overcome these critical issues, other investigations tried to identify the subjective experience of WHHRP using qualitative methods. Studies conducted in this way, mainly from a phenomenological perspective, use interviews or focus groups to understand the emotional and psychological burden reported by WHHRP (Pei-Fan, 2004; Leichtentritt et al., 2005; McCoyd et al., 2020). It has been found that inpatient women with Premature Rupture of Membranes experience anxiety and concern about the safety of the fetus, a more general perception of pending loss (Pei-Fan, 2004), as well as frustration for the patient condition, and loneliness due to separation from the family (Leichtentritt et al., 2005). However, although pregnant inpatients have reported high levels of stress related to gestational complications and consequent hospitalization, they tend not to express their concerns (McCoyd et al., 2020). Accepting the social norm that presents the pregnancy as a serene period, hospitalized women tend to control their emotions presenting themselves as "good patients" in order to receive optimal care (McCoyd et al., 2020).

As a result, the qualitative studies are of great interest to understand the content of emotions expressed by hospitalized pregnant women. However, given the subjectivity of experience, they cannot be quantitatively compared to a control group.

In our opinion, an approach that integrates quantitative and qualitative methods seems to be preferable to study not only the anxious and depressive symptom levels, but also the specific content of concerns that hospitalized women may experience due to high-risk pregnancy for preterm delivery.

The choice of using an integrative method seems relevant, especially in the Italian context where, despite the presence of quantitative studies on the theme (Pisoni et al., 2016), there is an absence of investigation on the subjective experience related to hospitalization. In the light of these considerations, the purpose of this study was to analyze, integrating quantitative and qualitative methods, the well-being and personal experience of WHHRP. The aims of this study were: a) to analyze the levels of depression, anxiety, and pregnancy-related anxiety in a group of WHHRP for preterm delivery; b) compare these aspects with those registered in a group of nonhospitalized women with LRP; c) describe the content of emotions of WHHRP for preterm delivery associated with the experience of hospitalization.

Regarding the first aim, we hypothesized that inpatient women would report higher levels of depression, anxiety, and pregnancy-related anxiety compared to women with LRP. Regarding the second aim, considering the paucity of results present in literature, especially in the Italian context, 
we preferred not to formulate specific hypotheses about the content of emotions, considering the purely exploratory nature of this objective.

\section{Method}

\section{Procedure and Participants}

A cross-sectional study was conducted. This study is a part of a larger longitudinal protocol and was carried out in a threelevel unit of a maternity ward in a University Hospital in Tuscany, Italy, from May to October 2019. The study was approved by the Institute's Ethics Committee (n.12749/2018).

Two groups of pregnant women were recruited from May to October 2019 in a three-level unit of a maternity ward in a University Hospital in Tuscany by the psychologist responsible for this study.

The Low-risk Pregnancy (LRP) group was enrolled according to specific inclusion criteria agreed with medical staff: maternal age $\geq 18$ and $<39$ years, singleton pregnancy, no evidence of any of the following conditions: gestational diabetes, hypertension, pre-eclampsia, congenital anomalies, premature rupture of membranes, intrauterine growth restriction, symptoms of premature birth (Bateman et al., 2013), followed in a routine prenatal care program, good comprehension of the Italian language.

Low-risk pregnant women were recruited while they were waiting for an routine obstetric visit at the University Hospital in Tuscany; they were asked to participate in the study and completed a battery of questionnaires.

Women hospitalized due to high-risk pregnancy (WHHRP) were enrolled according to specific inclusion criteria, agreed with medical staff, regarding the risk conditions for premature delivery associated with low infant birth weight, and other poor outcomes (World Health Organization, 2012). These criteria were: $\geq 18$ years old, hospitalized, with conditions of risk for preterm delivery and baby health (such as premature rupture of membranes, intrauterine growth restriction, symptoms of premature birth, twin pregnancy at risk), under 33 weeks of gestation. The cut-off of 33 weeks gestation was chosen because infants born before 33 weeks, defined "very preterm", are at higher risk for perinatal mortality, and neonatal complications (Tucker \& McGuire, 2004). Another inclusion criteria for the study was good comprehension of the Italian language.

Inpatient pregnant women were asked if they wanted to participate in the study at least 4 days after admission to the hospital; if they accepted, a battery of questionnaires was administered.

The clinical psychologist responsible for the study informed women of both groups about its aims. She specified that anonymity was guaranteed, participation was voluntary, they could withdraw from participation at any moment, and no monetary reward was given. All the hospitalized women contacted accepted participation; only $6 \%$ of the control group contacted refused participation.

The final sample was constituted by 61 pregnant women divided in two groups: 1) Low-risk pregnancy (LRP) group, 31 pregnant women aged from 23 to 39 years $(\mathrm{M}=32.9$; $\mathrm{SD}=4.57)$ between 21 and 32 weeks of gestation $(\mathrm{M}=27.8$; $\mathrm{SD}=3.4)$; 2) Hospitalized women due to high-risk pregnancy (WHHRP) group, 30 pregnant women aged from 23 to 47 years $(\mathrm{M}=34.1 ; \mathrm{SD}=5.89)$ between 19 and 32 weeks of gestation $(\mathrm{M}=27.13 ; \mathrm{SD}=4.4)$.

Women who agreed to participate signed the written consent form and completed questionnaires to register sociodemographical data, level of depression and anxiety, and pregnancy related anxiety. Only for hospitalized women, an additional questionnaire about the emotions they experienced during hospitalization was provided. Only completed questionnaires were accepted for this study.

\section{Measures}

Obstetric and clinical data (gestational age, type of pregnancy (single/twin), previous miscarriage, presence of assisted reproductive technology) were extracted by clinical record.

The battery of questionnaire was aimed to assess:

- Socio-demographical data, including age, educational level, employment status, marital status and parity.

- General anxiety. The Italian version (Iani et al., 2014) of the subscale of anxiety of Hospital Anxiety and Depression Scale (HADS-A) was used (Zigmond \& Snaith, 1983). The HADS-A is composed by 7 items requesting participants to respond how they have been feeling over the past seven days on a four-point scale (from 0 to 3 ). The total score of HADS-A ranges from 0 to 21 , with higher scores corresponding to a higher severity of anxious symptoms. This scale is a reliable instrument to assess anxious symptoms in pregnant women (Berle et al., 2005; Matthey \& Ross-Hamid, 2012) and it is generally used for detecting states of anxiety in the setting of a hospital medical outpatient clinic (Zigmond \& Snaith, 1983). In this sample, the Cronbach's alpha coefficient was .89 .

- Pregnancy related anxiety. The Pregnancy Related Anxiety Questionnaire-R (PRAQ-R) was used (Huizink et al., 2004; Italian version Dellagiulia et al., 2020). It is a 10 -items scale requesting respondents to indicate how often they experience anxious feelings related to pregnancy on a 5-point Likert scale ranging from 0 (never) to 4 (very often). It is composed by three subscale: worries about bearing a physically or mentally handicapped child (4 items), fear of giving birth (3 items) and concerns 
about own appearance (3 items). Moreover, PRAQ allows to obtain a global score about pregnancy related anxiety. Summated scores ranged from 0 to 16 for worries about bearing a physically or mentally handicapped child; from 0 to 12 for fear of giving birth and for concerns about own appearance; from 0 to 40 for total scale with higher scores meaning higher pregnancy related anxiety. In this sample, the Cronbach's alpha coefficient is and .88 for worries about bearing a physically or mentally handicapped child; .86 for fear of giving birth; .83 for concerns about own appearance; .79 for total scale.

- Prenatal Depression. The Italian version of the Edinburgh Postnatal Depression Scale was used to evaluate the level of depressive symptoms in pregnant women (EPDS; Cox et al., 1987; Benvenuti et al., 1999). EPDS has been widely used for screening for antenatal (Bunevicius et al., 2009), and beyond postnatal (Eberhard-Gran et al., 2001) depression, given the good psychometric properties. Respondents are required to indicate, for each of 10 items, how often they experienced depressive symptoms by rating them on a four-point scale (from 0 to 3). EPDS total score ranges from 0 to 30, with higher scores meaning a higher level of depressive symptoms. The cut-off $\geq 10$ has been used in this study to identify clinical depression according to studies in a community sample (Cox et al., 1987). In the present study, the Cronbach's alpha coefficient was .88 .

When the battery of questionnaires was completed, only the WHHRP women were asked to respond to 3 openended additional questions, through which they could provide more in-depth information about anxiety and depression, and the strategies used to cope with hospitalization. (Fribourg \& Rosenvinge, 2013). In particular, the questions had a neutral formulation to permit women to express both positive and negative feelings related to the experience of hospitalization from admission to present, and asked them to describe: 1) how they felt when they were admitted to the hospital; 2) how they were dealing with the hospitalization (feelings, emotions, coping strategies used...); 3) who or what they need at the present time during hospitalization.

\section{Data Analysis}

Quantitative data were analyzed using the Statistical Package for Social Sciences (SPSS), version 24 (2017). Comparisons between the two groups in sociodemographic, clinical and obstetrics data were performed with Student's $t$ test for independent data. Qualitative variables were summarized as counts and percentages and comparisons between groups were evaluated with Chi square test.
To compare the two groups on study variables, a series of univariate analyses of covariance (ANCOVAs), with the group as a fixed factor and the dimensions of the HADS-A, PRAQ and EPDS, and the variables significantly different between groups (type of pregnancy and use of assisted reproductive technologies) as covariate, were conducted. The alpha level was set to $p=.05$ for all tests with confidence interval at 95\%.

Qualitative data (answers to open-ended questions) were analyzed by two coders according to a global and qualitative level for content. The two coders read and re-read the transcript to identify themes, patterns, salient points, and to search for deviations and exceptions to trends (Bowling, 2014; Forrest Keenan et al., 2005). After reading the narratives, the two coders classified the content together, working to come to an agreement when their evaluations differed.

The aim was to discover the main themes concerning: a) the mothers' concerns and emotions related to the experience they were living as WHHRP, with particular attention to anxiety and depression; b) the way women sought to cope with hospitalization.

\section{Results}

Demographic, clinical and obstetric data of two groups are reported in Table 1.

No significant differences were found between WHHRP and LRP with respect to mean age $\left(\mathrm{t}_{(59)}=-.86 ; p=.32\right)$, mean gestational age $\left(\mathrm{t}_{(59)}=.68 ; p=.08\right)$, mean educational years level $\left(\mathrm{t}_{(59)}=1.80 ; p=.07\right)$, employment status $\left(\chi_{(3)}^{2}=.04\right.$; $p=.13)$, marital status $\left(\chi_{(1)}^{2}=1.05 ; p=.49\right)$, primigravidity $\left(\chi_{(1)}^{2}=2.29 ; p=.53\right)$, previous miscarriage $\left(\chi_{(1)}^{2}=1.50\right.$; $p=.18)$. On the contrary, the two groups differ for mode of conception $\left(\chi_{(1)}^{2}=6.63 ; p=.01\right)$, type of pregnancy $\left(\chi_{(1)}^{2}=\right.$ $9.51 ; p=.00)$.

Mean, standard deviation of all quantitative variables assessed and the results of the ANCOVAs analyses are reported in Table 2.

The first ANCOVA was performed using the score of the HADS-A. Results highlighted significant differences between WHHRP and LRP with the WHHRP reported higher levels of anxious symptoms then LRP despite the effect size of ANCOVA was moderate (Barbaranelli, 2007). The second ANCOVA, performed using the dimensions of the PRAQ-R as dependent variables, revealed no significant difference by group in fear of giving birth; worries about bearing a physically or mentally handicapped child; and pregnancy related anxiety (PRAQ-R total score). On the contrary significant differences merged in concerns about physical appearance with LRP reported higher levels of concerns about physical appearance than WHHRP despite the effect size of ANCOVA was moderate (Barbaranelli, 2007). Finally, the third 
Table 1 Demographic, obstetric and clinical characteristics of sample

\begin{tabular}{|c|c|c|c|}
\hline & WHHRP $(n=30)$ & $\operatorname{LRP}(n=31)$ & $\mathrm{P}$ \\
\hline Age, Mean (SD) & $34.1(5.9)$ & $32.9(4.57)$ & n.s. \\
\hline Educational level years, Mean (SD) & $16.2(4.4)$ & $18.1(3.8)$ & n.s. \\
\hline \multicolumn{3}{|l|}{ Employment status } & n.s. \\
\hline Unemployed & $3(10 \%)$ & 0 & \\
\hline Housewife & $12(40 \%)$ & $20(64,5 \%)$ & \\
\hline Permanent & $12(40 \%)$ & $9(29 \%)$ & \\
\hline Self-employed & $3(10 \%)$ & $2(6.5 \%)$ & \\
\hline \multicolumn{3}{|l|}{ Marital Status, n (\%) } & n.s. \\
\hline Married & $29(96,7 \%)$ & $31(100 \%)$ & \\
\hline Cohabiting & $1(3.3 \%)$ & 0 & \\
\hline Italian, n (\%) & $30(100 \%)$ & $31(100 \%)$ & n.s. \\
\hline Gestational weeks, Mean (SD) & $27.1(4.4)$ & $27.8(3.4)$ & n.s. \\
\hline \multicolumn{3}{|l|}{ Pregnancy, n (\%) } & .01 \\
\hline Single & $22(73.3 \%)$ & $31(100 \%)$ & \\
\hline Twin & $8(26.7 \%)$ & 0 & \\
\hline \multicolumn{3}{|l|}{ Conception, n (\%) } & .01 \\
\hline Spontaneous & $16(53.3 \%)$ & $26(83.9 \%)$ & \\
\hline Assisted reproductive technology & $14(46.7 \%)$ & $5(16.1 \%)$ & \\
\hline \multicolumn{3}{|l|}{ Primigravida, n (\%) } & n.s. \\
\hline Yes & $21(70 \%)$ & $21(67.7 \%)$ & \\
\hline No & $9(30 \%)$ & $10(32.3 \%)$ & \\
\hline \multicolumn{3}{|l|}{ Previous Miscarriage n (\%) } & n.s. \\
\hline No & $26(86.7 \%)$ & $23(74.2 \%)$ & \\
\hline Yes & $4(13.3 \%)$ & $8(25.8 \%)$ & \\
\hline \multicolumn{4}{|l|}{ Reason of hospedalization, $\mathrm{n}(\%)$} \\
\hline Premature Rupture Of Membranes & $6(20 \%)$ & & \\
\hline Risk of preterm delivery & $21(70 \%)$ & & \\
\hline Twin pregnancy at risk & $3(10 \%)$ & & \\
\hline
\end{tabular}

WHHRP, Women Hospitalized due to High-Risk Pregnancy; LRP, Low-Risk Pregnancy group

ANCOVA, conducted using the score of the EPDS, highlighted significant differences between WHHRP and LRP with the WHHRP reported higher levels of depressive symptoms than LRP with an elevate effect size (Barbaranelli, 2007).
The open-ended questions about hospitalization highlighted the anxieties and concerns of mothers, and the strategies they used to cope with hospitalization. The main themes that emerged from responses to the questions (Q) are reported

Table 2 Means and standard deviations of dimensions of the HADS-A, PRAQ-R, EPDS in two groups and ANCOVAs results

\begin{tabular}{|c|c|c|c|c|c|c|c|c|}
\hline & \multicolumn{2}{|c|}{ WHHRP } & \multicolumn{2}{|l|}{ LRP } & \multirow[b]{2}{*}{$D F$} & \multirow[b]{2}{*}{$F$} & \multirow[b]{2}{*}{$p$} & \multirow[b]{2}{*}{$\eta^{2}$} \\
\hline & $M$ & $S D$ & $M$ & $S D$ & & & & \\
\hline General anxiety (HADS-A) & 8.16 & 4.66 & 6.03 & 3.65 & 1,57 & 4.17 & .04 & .07 \\
\hline Worries about bearing a physically or mentally handicapped child (PRAQ) & 10.10 & 4.32 & 10.74 & 3.19 & 1,57 & .24 & .629 & .00 \\
\hline Anxiety about childbirth (PRAQ) & 7.06 & 3.32 & 8.32 & 2.98 & 1,57 & .67 & .418 & .01 \\
\hline Concerns about own appearance (PRAQ) & 4.43 & 1.87 & 5.71 & 2.55 & 1,57 & 5.32 & .025 & .09 \\
\hline Pregnancy related anxiety & 21.60 & 6.84 & 24.77 & 5.27 & 1,57 & 2.43 & .124 & .04 \\
\hline Perinatal Depression (EPDS) & 10.93 & 5.82 & 6.48 & 4.83 & 1,57 & 13.39 & .000 & .19 \\
\hline
\end{tabular}

WHHRP, Women Hospitalized due to High-Risk Pregnancy; LRP, Low-risk Pregnancy group 
below. Quotations are reported indicating identification number of women who expressed (\#nW).

Q1) How did they feel when they were admitted to the hospital?

\section{The moment of hospital admission: emotions of shock, worries and anxiety related to pregnancy}

Thirteen of the WHHRP (43\%) reported that admission to the hospital was unexpected and constituted a shock, a rupture in the self-biographical narrative, especially if the pregnancy had been proceeding regularly. At the time of admission, women reported fear, anxious feelings, worries, and concerns about the future of the pregnancy (i.e., "I felt really bad when I was admitted. I wasn't expecting it because things were all ok. Then in a week everything changed. The first thought goes to the child and you are so worried if something happens" $\#$ W.2).

Q2) How they were dealing with the hospitalization (feelings, emotions, coping strategies used...)?

\section{Hospitalization is understood and could be a protective factors for pregnancy-related anxiety}

After the first shocking impact with the hospital, fifteen of the women (50\%) recognized the importance of being hospitalized ("you realized that you were in the right place and you just have to arm yourself with strength and patience to overcome the obstacle" \#W23). On one hand, the hospitalization represents a protective factor for mother and fetus because they are " $100 \%$ controlled" (\#W11).Thus women reported a decrease of anxiety related to pregnancy and fetus health ("Inside [the hospital] I feel safe and I seem to better manage the anxiety of the three miscarriage threats that I experienced today" \#W9). Moreover six women (20\%) expressed appreciation toward medical personnel ("health professionals always provide attention and humanity" \#W12), and their ability to be reassuring about the ongoing pregnancy. Regarding this, one inpatient woman stated, "Here I found medical personnel who assisted and reassured me about the situation" (\#W23).

\section{Despite an Attempt to Understand the Hospitalization, Concerns, Anxiety and Fears Related to Pregnancy do Emerge}

Despite attempts to minimize the hospitalization and risks to pregnancy, ten women (33\%) recognized that they "are too worried that something [bad] will happen"(\#W.2). WHHRP try to live hospitalization "day after day, living in the moment, trying not to think about what can't be known, the future" (\#W11), leading us to suppose that they were faced with strong emotions that were difficult to manage. Women recognized that their attempts to think positively did not always produce hope and, consequently, their moods went up and down ("I spend the days thinking that I have been lucky and full of hope, and at other times fear takes over") (\#W24).

\section{Hospitalization Represents a Source of Stress}

Hospitalization marks the lack "of a comfort zone" represented by the home context. Being an inpatient in the hospital setting constituted a source of stress for seven women (23\%). Bed rest enhances the sensation of not being "completely self-sufficient" (\#W12), both physically and relationally. Even the most basic needs of self-care cannot to be satisfied ("I miss taking a shower at home, taking physical care of myself" (\#W23), reinforcing the perception of being vulnerable.

\section{Self-Blame for the Consequences of Hospitalization on Family Members}

Being an inpatient in the hospital constitutes for women a source of stress, anxiety and depressive feelings, due to the additional burden that falls on the family context. Six women of the sample (20\%) self-blamed for their condition of inpatient, which evoked concerns in family members ("I feel sorry for my parents, my partner, who worry about me" \#W9). Relatives worry about maternal and fetal health, and women think they must be strong for them too, and try to reassure them about their health and the ongoing pregnancy. Despite an attempt to be reassuring, sometimes women express difficulties to "manage the anxiety of relatives" (\#W15).

Moreover, hospitalization means that women are absent from the family context, and ten women $(33 \%)$ became concerned that they were not fulfilling their maternal role ("I have a 14-year-old boy at home ... I have to finish buying his school stuff, lining his books ... Even for the baby that will born I have to fix some things".\# W10). The family goes through reorganization, and women need to revise their central roles, delegating the management of the home and care of the children to their partners. For some, the greatest burden is "to delegate family commitments to my husband"(\#W21).

Q3) Who or what did they need during hospitalization? 


\section{Lack of Family, Support among Inpatients, and Need for Professional Emotional Support}

Nineteen hospitalized women (63\%) reported lack of family relationships. The physical distance and the lack of family support due to hospitalization led women to seek a source of support inside the hospital, primarily from other patients in the ward. Hospitalized pregnant women form an alliance, try to support one another, and make friends, because they feel the need to share similar situations and emotions. Emotional complicity developed among roommates allows them to express feelings and worries openly ("my roommate, the idea of never being alone, you put yourself in the other's shoes, you make friends" (\#W18).

Hospitalized women recognize that they must be positive to preserve fetal health, and when anxiety and sadness emerge, they express a sense of failure. Seven women of the sample (23\%) reported the need for "a competent person to talk to and make sense the situation, who makes me take the good news more importantly than the negative" (\#W29).

\section{Discussion}

This study aimed to analyze, integrating quantitative and qualitative approaches, the levels of general anxiety, pregnancyrelated anxiety, and perinatal depression in WHHRP, and to describe the specific content related to those feelings.

Results of this study have shown that WHHRP experience higher levels of general anxiety and perinatal depression than LPR, confirming a recent study in an Italian context (Pisoni et al., 2016). WHHRP reported clinical symptoms of depression) significantly higher (with an elevate effect size) than those reported by LRP.

Previous studies have shown that the diagnosis of gestational complications and consequent hospitalization may lead pregnant women to develop stress, anxiety, and depression (Gourounti et al., 2015; Guardino \& Schetter, 2014). The qualitative analysis allowed us to better understand this aspect, and it opened a window to consider these elements as risk factors to be managed with greater attention. Beginning upon admission, WHHRP reported a sense of shock, the perception that their pregnancy had become different from a "regular" one, and experienced reduced pleasure in the normally joyful experience of pregnancy. Women reported the loss of not being able to be close and involved with their partners and their (older) children. Feelings of loneliness and the difficulties associated with being away from home are reported by pregnant inpatient women (Leichtentritt et al., 2005). Although doctors prescribed bed rest, women would ideally like to contribute to housework and caregiving. They spend a lot of energy reassuring and praising partners and managing the emotions of all family members (McCoyd et al., 2020).
Regarding anxiety there was a moderate difference between LRP and HRP on concerns for own appearance. This data may be due to the low risk condition that lead women to focus on their own appearance during pregnancy compare to high risk condition that reported more worries associated with infant outcomes (Huizink et al., 2002; Rini et al., 1999).

On the contrary, no difference was found in WHHRP and those with LRP regarding the fears of giving birth, worries about bearing a physically or mentally handicapped child and pregnancy-related anxiety. In other words, hospitalization seems to constitute a protective factor for specific concerns, worries and anxieties related to pregnancy. Although this result could be surprising at first sight, the qualitative analysis allowed us to better understand how it is possible. Hospitalized women reported that they were reassured by the hospital context because it allowed them to be fully cared for and delegate the pregnancy outcome to medical professionals, expressing hope and trust in the medical staff (Leichtentritt et al., 2005).

However, another hypothesis cannot be excluded regarding our data. The lack of differences in pregnancy-related anxiety among women with low-risk and high-risk pregnancy (from questionnaire results) and the positive attitudes that inpatient women express about their hospitalization (from narrative results) may have been affected by two aspects. First, it is possible that, despite the concerns for their own and their baby's health, the women attempt to think positively. In fact, narratives confirm that women tend to not express distress about pregnancy to relatives, because they believe that family members are already overburdened. It is possible that women try to convince themselves, in addition to family members, about the wellness of the pregnancy. On the other hand, it is possible that hospitalized women moderated the expression of their pregnancy anxiety, given that the questionnaire was administered by the responsible for the study, who was the hospital psychologist. Thus, the hospitalized women, perceiving the study investigator as a medical provider (although not their provider), may have moderated the expression of their pregnancy anxiety in an attempt to be considered a good "mother" and a "good patient" (McCoyd et al., 2020). The fact that women were recruited while they were inpatients in a hospital may have led them to recall mainly the positive aspects of the hospitalization, and that they were fully cared for by professionals (as reported in narratives and pregnancy-related anxiety questionnaires). Efforts to be a good patient might merely be an attempt to elicit optimal care (Munch et al., 2020), although not all women are able to think positively.

Despite attempts to minimize the risk for their pregnancy, they believe that they are in the right place for their condition, and express trust in medical doctors. However, the women did report a desire for a higher level of attention to their emotions, and a wish for professionals to make the positive aspects more important than the negative ones, revealing ambivalent 
feelings (Leichtentritt et al., 2005). This leads us to suppose that inpatient women with high-risk pregnancies face strong emotion management challenges that can overwhelm their coping capacities. Within a dialectical conflict between their maternal identity and their patient roles, these women use emotion control as a dysfunctional coping strategy, thus increasing the psychological burden of the hospitalization experience (McCoyd et al., 2020).

The main source of support inside the hospital setting is represented by roommates who share the same condition of being hospitalized women with high-risk pregnancies. Despite the emotional complicity and alliances formed between hospitalized women, which helps them face the "patient" role, this support is not sufficient. In fact, inpatient women express the need for "a competent person to talk and make sense- the situation, who will make me take the good news more importantly than the negative" (\#W29). On one hand, this seems to indicate greater attention to emotional experience followed by a trained professional. On the other hand, our results suggest that the quality of patient-doctor communication should also be reconsidered. Health professionals should be aware that their communications with patients, reassuring about the pregnancy and the health of the woman and fetus, may not reduce maternal concerns and anxieties (Barber \& Starkey, 2015). In fact, women may cognitively overcome the pregnancy-related anxieties, but other sources of anxiety and concerns are reported. For example, missing her partner and older children, losing the central role in the family, and self-blaming related to being hospitalized constitute psychological burdens not improved by medical communication focused on pregnancy. Greater attention to the emotional experience of patients may lead medical professionals to recognize women who are at higher risk of early depressive and anxiety symptoms, so that they can activate emotional support to help them cope with hospitalization in a more functional way (Pei-Fan, 2004; Leichtentritt et al., 2005; Pozzo et al., 2010; McCoyd et al., 2020). Midwives could be mediators between doctors and patients to recognize women who show significant levels of anxiety and depression (Currie \& Barber, 2016) and report these cases to a clinical psychologist. The presence of a psychologist in the gynecology and obstetrics ward would be an important resource, not only to support inpatient women in expressing their emotions, but also to help health professionals by functioning as communication facilitators with patients (Pozzo et al., 2010). Moreover, a psychologist present in the gynecology and obstetrics ward could identify depressive, anxious, and stress symptoms in high-risk pregnancies, thereby reducing health and social costs (Gourounti et al., 2015). The clinical psychologist may be useful in Gynecology and Obstetrics wards as evidenced by the clinical depressive symptoms of WHHRP. The psychologist's ability is to analyze the narratives of emotional experiences that bring out the differences between these women beyond the more classic depressive symptomology. The identification of anxious and depressive symptoms should take place by integrating quantitative (screening tools) and qualitative (interview, open ended questions...) methods because, as shown in the present study, the questionnaires on their own are not able to completely detect anxious feelings related to pregnancy in women hospitalized due to high-risk pregnancy.

Despite its relevance, this study presents some limitations. First, the sample size is small, given that it is constituted by women at high risk for preterm delivery. However, the homogeneity of sample may constitute a positive element of this investigation given that it overcomes previous study limitations. Second, this is a cross section study. Thus, we cannot know how the anxious or depressive symptoms change during hospitalization. Future studies should be conducted to analyze how the emotional experiences of women change at different time points of hospitalization. Moreover, we did not collect the data about the length of hospitalization and therefore cannot analyze how the symptoms vary depending by the length of stay.

Despite these limitations, this is the first study to our knowledge that, by integrating quantitative and qualitative methods, explores symptoms of depression, anxiety and pregnancy-specific anxiety of WHHRP for preterm delivery and collects the nature of their concerns, especially in the Italian context. The results are extremely interesting and suggest we continue to explore these issues through clinical interviews, in order to identify the main themes reported by women. This investigation will allow us to direct specific and targeted interventions on the main concerns that these women experience, helping them to better live the delicate moment of transition to motherhood.

Acknowledgments This research was made possible thanks to the financial support of Casamadre onlus (Grant 549901_2019).

Funding Open access funding provided by Università di Pisa within the CRUI-CARE Agreement.

Data Availability Data are available by authors under reasonable request.

\section{Declarations}

Disclosure Statement The authors declare they have no conflict of interest.

Open Access This article is licensed under a Creative Commons Attribution 4.0 International License, which permits use, sharing, adaptation, distribution and reproduction in any medium or format, as long as you give appropriate credit to the original author(s) and the source, provide a link to the Creative Commons licence, and indicate if changes were made. The images or other third party material in this article are included in the article's Creative Commons licence, unless indicated otherwise in a credit line to the material. If material is not included in the article's Creative Commons licence and your intended use is not permitted by 
statutory regulation or exceeds the permitted use, you will need to obtain permission directly from the copyright holder. To view a copy of this licence, visit http://creativecommons.org/licenses/by/4.0/.

\section{References}

Barbaranelli, C. (2007). Analisi dei dati: tecniche multivariate per la ricerca psicologica e sociale. Edizioni universitarie di lettere economia diritto.

Barber, C. C., \& Starkey, N. (2015). Predictors of anxiety among pregnant New Zealand women hospitalized for complications and a community comparison group. Midwifery, 31(9), 888-896. https:// doi.org/10.1016/j.midw.2015.04.017.

Bateman, B. T., Mhyre, J. M., Hernandez-Diaz, S., Huybrechts, K. F., Fischer, M. A., Creanga, A. A., Callaghan, W. M., \& Gagne, J. J. (2013). Development of a comorbidity index for use in obstetric patients. Obstetrics and Gynecology, 122, 957-965. https://doi. org/10.1097/AOG.0b013e3182a603bb.

Behrman, R. E., Butler A. S. (Eds.) (2007). Preterm birth: causes, consequences, and prevention, National Academies Press.

Benvenuti, P., Ferrara, M., Niccolai, C., Valoriani, V., \& Cox, J. L. (1999). The Edimburgh postnatal depression scale: Validation for an Italian sample. Journal of Affective Disorders, 53(2), 137-141. https://doi.org/10.1016/S0165-0327(98)00102-5.

Berle, J. Ø., Mykletun, A., Daltveit, A. K., Rasmussen, S., Holsten, F., \& Dahl, A. A. (2005). Neonatal outcomes in offspring of women with anxiety and depression during pregnancy. A linkage study from the Nord-Trøndelag health study (HUNT) and medical birth registry of Norway. Archives of Women's Mental Health, 8(3), 181-189. https://doi.org/10.1007/s00737-005-0090-z.

Bibring, G. L. (1959). Some considerations of the psychological processes in pregnancy. The Psychoanalytic Study of the Child, 14(1), 113121. https://doi.org/10.1080/00797308.1959.11822824.

Bowling, A. (2014). Research methods in health: investigating health and health services. McGraw-hill education (UK).

Bunevicius, A., Kusminskas, L., Pop, V. J., Pedersen, C. A., \& Bunevicius, R. (2009). Screening for antenatal depression with the Edinburgh depression scale. Journal of Psychosomatic Obstetrics and Gynecology, 30(4), 238-243.

Byatt, N., Hicks-Courant, K., Davidson, A., Levesque, R., Mick, E., Allison, J., \& Moore Simas, T. A. (2014). Depression and anxiety among high-risk obstetric inpatients. General Hospital Psychiatry, 36(6), 644-649. https://doi.org/10.1016/j. genhosppsych.2014.07.011.

Class, Q. A., Lichtenstein, P., Långström, N., \& D'Onofrio, B. M. (2011). Timing of prenatal maternal exposure to severe life events and adverse pregnancy outcomes: A population study of 2.6 million pregnancies. Psychosomatic Medicine, 73(3), 234-241. https://doi.org/ 10.1097/PSY.0b013e31820a62ce.

Cox, J. L., Holden, J. M., \& Sagovsky, R. (1987). Detection of postnatal depression. Development of the 10-item Edinburgh postnatal depression scale. The British Journal of Psychiatry: the Journal of Mental Science, 150, 782-786. https://doi.org/10. 1192/bjp.150.6.782.

Currie, J., \& Barber, C. C. (2016). Pregnancy gone wrong: Women's experiences of care in relation to coping with a medical complication in pregnancy. New Zealand College of Midwives Journal, 52, 3540. https://doi.org/10.12784/nzcomjnl52.2016.5.35-40.

Dagklis, T., Papazisis, G., Tsakiridis, I., Chouliara, F., Mamopoulos, A., \& Rousso, D. (2016). Prevalence of antenatal depression and associated factors among pregnant women hospitalized in a high-risk pregnancy unit in Greece. Social Psychiatry and Psychiatric
Epidemiology, 51(7), 1025-1031. https://doi.org/10.1007/s00127016-1230-7.

Dellagiulia, A., Lionetti, F., Pastore, M., Linnea, K., Hasse, K., \& Huizink, A. C. (2020). The pregnancy anxiety questionnaire Revised-2: A contribution to its validation. European Journal of Psychological Assessment, 36(5), 787-795. https://doi.org/10. 1027/1015-5759/a000559.

Denis, A., Michaux, P., \& Callahan, S. (2012). Factors implicated in moderating the risk for depression and anxiety in high risk pregnancy. Journal of Reproductive and Infant Psychology, 30(2), 124-134. https://doi.org/10.1080/02646838.2012.677020.

Eberhard-Gran, M., Eskild, A., Tambs, K., Opjordsmoen, S., \& Samuelsen, S. O. (2001). Review of validation studies of the Edinburgh postnatal depression scale. Acta Psychiatrica Scandinavica, 104, 243-249.

Fairbrother, N., Young, A. H., Zhang, A., Janssen, P., \& Antony, M. M. (2016). The prevalence and incidence of perinatal anxiety disorders. Archives of Women's Mental Health, 20(2), 311-319. https://doi. org/10.1007/s00737-016-0704-7.

Forrest Keenan, K., van Teijlingen, E., \& Pitchforth, E. (2005). The analysis of qualitative research data in family planning and reproductive health care. The Journal of Family Planning and Reproductive Health Care, 31(1), 40-43. https://doi.org/10.1783/ 0000000052972825

Fribourg, O., \& Rosenvinge, J. H. (2013). A comparison of open-ended and closed questions in the prediction of mental health. Quality and Quantity: International Journal of Methodology, 47(3), 1397-1411. https://doi.org/10.1007/s11135-011-9597-8.

Gourounti, K., Karpathiotaki, N., \& Vaslamatzis, G. (2015). Psychosocial stress in high risk pregnancy. International Archives of Medicine, 8, 1-9. https://doi.org/10.3823/1694.

Guardino, C. M., \& Schetter, C. D. (2014). Coping during pregnancy: A systematic review and recommendations. Health Psychology Review, 8(1), 70-94. https://doi.org/10.1080/17437199.2012. 752659.

Hennekam, S. (2016). Identity transition during pregnancy: The importance of role models. Human Relations, 69(9), 1765-1790. https:// doi.org/10.1177/0018726716631402.

Huizink, A. C., Robles De Medina, P. G., Mulder, E. J. H., Visser, G. H. A., \& Buitelaar, J. K. (2002). Psychological measures of prenatal stress as predictors of infant temperament. Journal of the American Academy of Child and Adolescent Psychiatry, 41, 1078-1085. https://doi.org/10.1097/00004583-200209000-00008.

Huizink, A. C., Mulder, E. J., de Medina, P. G. R., Visser, G. H., \& Buitelaar, J. K. (2004). Is pregnancy anxiety a distinctive syndrome? Early Human Development, 79(2), 81-91.

Iani, L., Lauriola, M., \& Costantini, M. (2014). A confirmatory bifactor analysis of the hospital anxiety and depression scale in an Italian community sample. Health and Quality of Life Outcomes, 5, 12-84. https://doi.org/10.1186/1477-7525-12-84.

James, D. K., Steer, P. J., Weiner, C. P., \& Gonik, B. (2010). High risk pregnancy e-book: Management options-expert consult. Elsevier Health Sciences.

Kralik, D., Visentin, K., \& van Loon, A. (2006). Transition: A literature review. Journal of Advanced Nursing, 55(3), 320-329. https://doi. org/10.1111/j.1365-2648.2006.03899.x.

Leichtentritt, R. D., Blumenthal, N., Elyassi, A., \& Rotmensch, S. (2005). High-risk pregnancy and hospitalization: The Women's voices. Health \& Social Work, 30(1), 39-47. https://doi.org/10.1093/hsw/ 30.1.39.

Maloni, J. A. (2010). (2010). Antepartum bed rest for pregnancy complications: Efficacy andsafety for preventing preterm birth. Biological Research for Nursing, 12(2), 106-124. https://doi.org/10.1177/ 1099800410375978.

Matthey, S., \& Ross-Hamid, C. (2012). Repeat testing on the Edinburgh depression scale and the HADS-A inpregnancy: Differentiating 
between transient andenduring distress. Journal of Affective Disorders, 141(2-3), 213-221. https://doi.org/10.1016/j.jad.2012. 02.037 .

McCoyd, J. L. M., Curran, L., \& Munch, S. (2020). They say, "if you don't relax...you're going to make something bad happen": Women's emotion management during medically high-risk pregnancy. Psychology of Women Quarterly, 44(1), 117-129. https:// doi.org/10.1177/0361684319883199.

Munch, S., McCoyd, J. L. M., Curran, L., \& Harmon, C. (2020). Medically high-risk pregnancy: Women's perceptions of their relationships with health care providers. Social Work in Health Care, 59(1), 20-45. https://doi.org/10.1080/00981389.2019.1683786.

Pei-Fan, M. (2004). Maternal role transition experiences of women hospitalized. International Journal of Nursing Studies, 41(8), 825-832. https://doi.org/10.1016/j.jinurstu.2004.03.008.

Pisoni, C., Garofoli, F., Tzialla, C., Orcesi, S., Spinillo, A., Politi, P., Balottin, U., Tinelli, C., \& Stronati, M. (2016). Complexity of parental prenatal attachment during pregnancy at risk for preterm delivery. Journal of Maternal-Fetal and Neonatal Medicine, 29(5), 771-776. https://doi.org/10.3109/14767058.2015.1017813.

Pozzo, M. L., Brusatic, V., \& Cetin, I. (2010). Clinical relationship and psychological experience of hospitalization in "high-risk" pregnancy. European Journal of Obstetrics \& Gynecology and Reproductive Biology, 149, 136-142. https://doi.org/10.1016/j. ejogrb.2009.12.009.
Queenan, J. T. (2012). Management of high-risk pregnancy. John Wiley and sons ltd.

Rini, C. K., Dunkel-Schetter, C., Wadhwa, P. D., \& Sandman, C. A. (1999). Psychological adaptation and birth outcomes: The role of personal resources, stress, and sociocultural context in pregnancy. Health Psychology, 18, 333-345.

Smorti, M., Ponti, L., \& Pancetti, F. (2019). A comprehensive analysis of post-partum depression risk factors: The role of socio-demographic, individual, relational, and delivery characteristics. Frontiers Public Health, 7, 295. https://doi.org/10.3389/fpubh.2019.00295.

Thiagayson, P., Krishnaswamy, G., Lim, M. L., Sung, S. C., Haley, C. L., Fung, D. S., Allen Jr., J. C., \& Chen, H. (2013). Depression and anxiety in Singaporean high-risk pregnancies - prevalence and screening. General Hospital Psychiatry, 35(2), 112-116. https:// doi.org/10.1016/j.genhosppsych.2012.11.006.

Tucker, J., \& McGuire, W. (2004). Epidemiology of preterm birth. BMJ, 329, 675-678. https://doi.org/10.1136/bmj.329.7467.675.

World Health Organization. (2012). Born too soon: The global action report on preterm birth.

Zigmond, A. S., \& Snaith, R. P. (1983). The hospital anxiety and depression scale. Acta Psychiatrica Scandinavica, 67(6), 361-370.

Publisher's Note Springer Nature remains neutral with regard to jurisdictional claims in published maps and institutional affiliations. 